\title{
Revista \\ Perspectivas de Políticas Públicas
}

Los procesos políticos y sociales que se desarrollaron desde principios del siglo en curso se proyectaron hacia la reconfiguración del Estado y sus modalidades de relación con la sociedad. Este número enfoca algunos de esos cambios en varias dimensiones de el accionar del Estado y las relaciones que a partir de ellos tienen lugar con respecto a ciertos actores sociales y políticos.

Los artículos de Gabriel Calvi y de Giuseppe Messina enfocan este asunto en el terreno de la intervención estatal en la distribución del ingreso durante las últimas dos décadas y en el campo de la salud pública, respectivamente, contrastando el "antes" y "después" que marcaron, desde 2003, los gobiernos kirchneristas, así como las persistencias de ciertos ingredientes de los diseños y estilos anteriores en los nuevos escenarios institucionales. Un elemento importante de las reorientaciones "post neoliberales" corresponde al reconocimiento institucional de actores hasta entonces marginados, así como el estímulo a la incorporación de organizaciones y movimientos sociales a variados niveles de implementación de políticas encaminadas a procesar las demandas de esos mismos actores. Los textos de Gradin y Natalucci argumentan sobre las proyecciones y limitaciones de estos experimentos tanto en lo que respecta a las políticas específicas como a las tensiones y conflictos de mayor alcance en lo que refiere a los respectivos proyectos de poder; por su parte, Schamber presenta el proceso y los elementos que condujeron desde la represión inicial al reconocimiento institucional progresivo de los cartoneros en la ciudad de Buenos Aires.

Gran parte de los análisis de la crisis del régimen de convertibilidad se ha centrado en su impacto en los sectores medios y de menores ingresos, o bien en aspectos macroeconómicos. El artículo de Eduardo Gálvez enfoca un aspecto poco trabajado: la gravitación de esa crisis en los grupos empresariales y sus esfuerzos de recomponer una hegemonía cuestionada por la propia crisis y por su participación en diferentes momentos previos. La habilidad para adaptarse a escenarios diversos no es exclusiva de estos actores. Federico Saettone destaca la eficacia del Partido Justicialista, desde los momentos iniciales de su existencia, para armonizar tendencias y diferencias internas: una eficacia que ha podido mantener hasta la actualidad.

El Director 